\title{
Role of Globalisation in Women's Health: A Key Issue
}

\author{
Neelesh Pandey \\ Research Scholar, Department of Journalism and Mass Communication \\ Central University of Orissa, Koraput, India
}

oScholedge International Journal of Multidisciplinary \& Allied Studies (2394-336X), Vol.03, Issue 02 (2016) pg63-66. Published by: Scholedge R\&D Center [www.theSCHOLEDGE.org] [Email: sijmas@scholedge.org]

\begin{abstract}
The health of Indian women is intrinsically linked to their status in society. Research on women's status has found that the contributions Indian women make to families often are overlooked, and instead they are viewed as economic burdens. There is a strong son preference in India, as sons are expected to care for parents as they age. This son preference, along with high dowry costs for daughters, sometimes results in the mistreatment of daughters. Further, Indian women have low levels of both education and formal labor force participation. They typically have little autonomy, living under the control of first their fathers, then their husbands, and finally their son. All of these factors exert a negative impact on the health status of Indian women. Poor health has repercussions not only for women but also their families. Women in poor health are more likely to give birth to low weight infants. They also are less likely to be able to provide food and adequate care for their children. Finally, a woman's health affects the household economic well-being, as a woman in poor health will be less productive in the labor force. While women in India face many serious health concerns, this profile focuses on only five key issues: reproductive health, violence against women, nutritional status, unequal treatment of girls and boys, and HIV/AIDS. Because of the wide variation in cultures, religions, and levels of development among India's 25 states and 7 union territories, it is not surprising that women's health also varies greatly from state to state. To give a more detailed picture, data for the major states will be presented whenever possible. The discrimination against the girl child is systematic and pervasive enough to manifest in many demographic measures for the country. For the country as a whole as well as its rural areas, the infant mortality rate is higher for females in comparison to that for males. Usually, though not exclusively, it is in the northern and western states that the female infant mortality rates are higher, a difference of ten points between the two sexes specific rates not being uncommon.
\end{abstract}

Keywords: - Globalization, Women, Health Service, Health Information

\section{Introduction}

The health of Indian women is intrinsically linked to their status in society. Research on women's status has found that the contributions Indian women make to families often are overlooked, and instead they are viewed as economic burdens. There is a strong son preference in India, as sons are expected to care for parents as they age. This son preference, along with high dowry costs for daughters, sometimes results in the mistreatment of daughters. Further, Indian women have low levels of both education and formal labor force participation. They typically have little autonomy, living under the control of first their fathers, then their husbands, and finally their son. All of these factors exert a negative impact on the health status of Indian women. Poor health has repercussions not only for women but also their families. Women in poor health are more likely to give birth to low weight infants. They also are less likely to be able to provide food and adequate care for their children. Finally, a woman's health affects the household economic well-being, as a woman in poor health will be less productive in the labor force. While women in India face many serious health concerns, this profile focuses on only five key issues: reproductive health, violence against women, nutritional status, unequal treatment of girls and boys, and HIV/AIDS. Because of the wide variation in cultures, religions, and levels of development among India's 25 states and 7 union territories, it is not surprising that women's health also varies greatly from state to state. To give a more detailed picture, data for the major states will be 
presented whenever possible. The discrimination against the girl child is systematic and pervasive enough to manifest in many demographic measures for the country. For the country as a whole as well as its rural areas, the infant mortality rate is higher for females in comparison to that for males. Usually, though not exclusively, it is in the northern and western states that the female infant mortality rates are higher, a difference of ten points between the two sex specific rates not being uncommon. The infant mortality rate is slightly in favour of females in the urban areas of the country (as a whole) But then, urban India is marked by greater access to abortion services and unwanted girl children often get eliminated before birth. It has been commented in the context of women's health that sustainable well-being can be brought about if strategic interventions are made at critical stages.

The life cycle approach thus advocates strategic interventions in periods of early childhood, adolescence and pregnancy, with programmes ranging from nutrition supplements to life skills education. Such interventions attempt to break the vicious intergenerational cycle of ill health. The vulnerability of females in India in the crucial periods of childhood, adolescence and childbearing is underscored by the country's sex wise age specific mortality rates. From childhood till the mid twenties, higher proportions of women than men die in the country. In rural India, higher proportions of women die under thirty. Like most cultures across the world, Indian society has deeply entrenched patriarchal norms and values. Patriarchy manifests itself in both the public and private spheres of women's lives in the country, determining their 'life chances' and resulting in their qualitatively inferior status in the various socio-economic spheres. It permeates institutions and organisations and works in many insidious ways to undermine women's right to dignified lives. There are similarities in women's lived experiences due to such gendered existences. However, in a vast and sociocultural heterogeneous country like India, women's multiple and often special needs are played out on a variegated terrain of age, caste, class and region resulting in a complexity of experiences. Traditional bases of social stratification such as caste and class reproduce themselves in women's lived experiences as also do rural-urban and regional disparities. New needs emerge as women progress through the life cycle. Talking about women's health and access to healthcare in such a complex setup thus poses a challenge.

\section{Access to Health Services}

Women's health needs differ from men because of biological differences and also as a result of gender differentials in exposure to risk factors. Therefore they are more vulnerable due to the impacts of globalization. The four factors, which determine women's access to health care are: Extent of ill health amongst women; Promotion - crucial factors influencing whether women can seek health care; Ability economic factors enabling women to meet the cost of health services; and Availability - the network of health services and access to it.

\section{Formal healthcare}

The formal healthcare setup in India is huge and diverse. Sectoral plurality and functional diversities mark the provisioning of healthcare in the country. The privileging of the biomedical model in medical colleges across the country reflects in various ways, ranging from textbooks that are often gender blind/ insensitive to providers' attitudes that may display lack of understanding of socioeconomic causes underlying ill health. The public sector has a considerable and diverse physical presence, largely owing to the gains made prior to the 1990s. The public healthcare infrastructure ranges from a sub-centre in a village to multi-specialty, multibedded hospitals in urban areas. Primary Health Centers, Rural Hospitals, Civil Hospitals as well as a host of facilities like municipal hospitals and clinics are some of the other public healthcare facilities. The state may also run health facilities dedicated to specific diseases (for example, leprosy clinics) or specific population sub groups (for instance, Central Government Health Scheme). The structure of the public health sector is thus fairly well defined. In the 1990s, there has been uneven growth in the number of Community Health Centres (CHCs), Primary Health Centres (PHCs) and Subcenters (SCs) in the different states and union territories of India. While some states have witnessed considerable increase in such facilities, the progress has been very slow or stagnant in others. For the country as a whole, tribal areas are deficient in the three types of public

http://dx.doi.org/10.19085/journal.sijmas030204 
facilities set up for providing primary healthcare, the deficiency being severe for Community Health Centres. Barring a few states and union territories, the others have deficiencies in the three types of public facilities.

\section{Nutrition}

Nutrition is a determinant of health. A well balanced diet increases the body's resistance to infection, thus warding off a host of infections as well as helping the body fight existing infection. Depending on the nutrient in question, nutritional efficiency can manifest in an array of is orders like protein energy malnutrition, night blindness, and iodine deficiency is orders, anaemia, and stunting, low Body mass Index and low birth weight. Improper nutritional intake is also responsible for is eases like coronary heart disease, hypertension, non-insulin dependent diabetes mellitus and cancer, among there. Nutritional deficiency disorders of different types are widely prevalent in the countries of south East Asia, with some pockets showing infelicity in certain types of disorders. iodine deficiency disorder is endemic to the Himalayan and several tribal areas and anaemia is a pervasive problem across most socio-economic groups of the country

\section{Information Needs of Women}

Information needs of women in the new globalized environment are as diverse as the socio- economic scenario. Treating women, as a monolithic group will over simplify their information needs. Within women's group itself, globalisation has created the haves and the have notes i.e those who are in an advantageous position due to globalisation and those relegated further into disadvantaged position under the new economic policy. The information needs will also differ accordingly.

The urban educated women need information mainly pertaining to:

- Research

- Educational opportunities including prospects abroad

- Career advancement facilities

- Job/ employment prospects in India and abroad

- Matrimonial

- Fashion and market values

- Health and child care facilities which includes sexual and reproductory information

- Art and entertainment

- Social support system for working women

\section{Conclusion}

Women's empowerment is hindered by limited autonomy in many areas that has a strong bearing on development. Their institutionalised incapacity owing to low levels of literacy, limited exposure to mass media and access to money and restricted mobility results in limited areas of competence and control (for instance, cooking). The family is the primary, if not the only locus for them. However, even in the household domain, women's participation is highly gendered. Nationally, about half the women (51.6\%) are involved in decision making on their healthcare. Women's widespread ignorance about matters related to their health poses a serious impediment to their well-being. The NFHS-2, for example, reports that out of the total births where no 
antenatal care was sought during pregnancy, in 60 percent of the cases women felt it was 'not necessary'. And, at a time when AIDS is believed to have assumed pandemic proportions in the country, 60 percent of the ever married women have never heard of the disease. Women's inferior status thus has deleterious effects on their health and limits their access to healthcare. The household has been seen to be a prominent site for gender based discrimination in matters of healthcare in a number of other studies too. Marriage in India is predominantly patrilocal with the new bride relocating to her marital house after marriage. Early marriage usually follows a truncated education, disadvantaging girls in many ways. In such a setup, the new bride, already ignorant about health processes, may be in a difficult position to seek healthcare. Basua and Kurz report from their study on married adolescent girls in Maharashtra that 'girls had neither decision making power nor influence' in matters relating to seeking healthcare for their problems. These illnesses that incapacitated girls from discharging their household responsibilities were treated quickly. The culture of silence prevented care seeking in problems related to sexual health. Some reproductive health problems went untreated because they were considered 'normal'. In the Nasik study by Madhiwalla, et.al, $45 \%$ of the episodes of ill health in women went untreated.

\section{Reference}

1. Chatterjee Meera, Indian Women: Their Health and Economic Productivity, World Bank Discussion Papers 109, Washington, DC. (1990)

2. Shetty P.S., Food and nutrition. In Detels, R., J. McEwen, R. Beaglehole and H. Tanaka (eds.) Oxford Textbook of Public Health (fourth edition), New York: Oxford University Press, 149-170 (2004)

3. Duggal R., Health and nutrition in Maharashtra. In Government of Maharashtra (2002). Human Development Report: Maharashtra, New Delhi: Oxford University Press, 53-77 (2002)

4. Mishra M., Duggal R. and Raymus P., Health and healthcare situation in Jalna, Yawatmal and Nandurbar.(Report submitted to the Indira Gandhi Institute for Development Research (IGIDR), Mumbai as part of the Maharashtra Human Development Report Followup Study sponsored by the UNDP, New Delhi, and the State Planning Board, Government of Maharashtra). Mumbai: Centre for Enquiry into Health and Allied Themes (CEHAT) (2004)

5. Dube L., on the construction of gender: Hindu girls in patrilineal India. In Karuna Channa (ed.) Socialisation, Education and Women: Explorations in Gender Identity. New Delhi: Orient Longman 166-192 (1988)

6. Nandraj S., Beyond the Law and the Lord: Quality of Private Health Care. Economic and Political Weekly, 29(27), 1680-1685 (1994)

7. Basu A. and Kurz. K., Reproductive health seeking by married adolescent girls in Maharashtra, India, Reproductive Health Matters, 9(17), 52-62 (2001)

8. Victoria A. Velkoff and Arjun Adlakha. (1998). Women of the World Women's Health in India. Retrieved February 7 , 2011 from http://www.census.gov/ipc/prod/wid- 9803.pdf

9. Sunilkumar M Kamalapur1 and Somanath Reddy. (2013) Retrieved January 2016 from http://www.isca.in/IJSS/Archive/v2/110/3.ISCA-IRJSS-2013-135.pdf

10. Women health retrieved on January 2016 from http://cdcmp.org/project-program/women-s-health

11. Cost and Consequences of Sedentary Living: New Battleground for an Old Enemy retrieved on January 2016 from https://www.presidentschallenge.org/informed/digest/docs/ 200203 digest.pdf

11. Madhiwalla N., Nandraj S. and Sinha R., Health households and women's lives: A study of illness and childbearing among women in Nashik district, Maharashtra. Mumbai: Centre for Enquiry into Health and Allied Themes (CEHAT) (2000).

http://dx.doi.org/10.19085/journal.sijmas030204 